\title{
Author Correction: Alleviation of drought stress in pulse crops with ACC deaminase producing rhizobacteria isolated from acidic soil of Northeast India
}

\author{
Juthika Saikia ${ }^{1}$, Rupak K. Sarma ${ }^{1}$, Rajashree Dhandia ${ }^{1}$, Archana Yadav $^{1}$, Rupjyoti Bharali $^{2}$, \\ Vijai K. Gupta ${ }^{3}{ }^{3}$ \& Ratul Saikia ${ }^{1}$
}

Correction to: Scientific Reports https://doi.org/10.1038/s41598-018-21921-w, published online 23 February 2018

In this Article, Vijai K. Gupta is incorrectly listed as being affiliated with 'Applied Biology and Biopharmaceutical Science, School of Science \& Computing, Galway-Mayo Institute of Technology, Galway, Ireland'

The correct affiliation is listed below:

'Department of Chemistry and Biotechnology, ERA Chair of Green Chemistry, Tallinn University of Technology, Tallinn 12618, Estonia'

This error has now been corrected in the PDF and HTML versions of the Article, and in the Supplementary Information file.

(i) Open Access This article is licensed under a Creative Commons Attribution 4.0 International License, which permits use, sharing, adaptation, distribution and reproduction in any medium or format, as long as you give appropriate credit to the original author(s) and the source, provide a link to the Creative Commons license, and indicate if changes were made. The images or other third party material in this article are included in the article's Creative Commons license, unless indicated otherwise in a credit line to the material. If material is not included in the article's Creative Commons license and your intended use is not permitted by statutory regulation or exceeds the permitted use, you will need to obtain permission directly from the copyright holder. To view a copy of this license, visit http://creativecommons.org/licenses/by/4.0/.

(C) The Author(s) 2018

\footnotetext{
${ }^{1}$ Biotechnology Group, Biological Sciences and Technology Division, CSIR-North East Institute of Science and Technology, Jorhat, 785006, Assam, India. '2Department of Biotechnology, Gauhati University, Guwahati, 781014, Assam, India. ${ }^{3}$ Department of Chemistry and Biotechnology, ERA Chair of Green Chemistry, Tallinn University of Technology, Tallinn, 12618, Estonia. Juthika Saikia, Rupak K. Sarma and Rajashree Dhandia contributed equally to this work. Correspondence and requests for materials should be addressed to R.S. (email: rsaikia19@gmail.com)
} 